\title{
Influence of Training Lessons on Change of Value-Rational Component of Psychological Culture of Students of Early Young age
}

\author{
Natalia Pavlovna Kondratyeva ${ }^{1 *}$, Yulia Vladimirovna Vardanyan ${ }^{1}$, Maria Sergeevna Dementieva ${ }^{1}$, Lyudmila \\ Valeryevna Vardanyan ${ }^{1}$ \\ ${ }^{I}$ Mordovia State Pedagogical Institute named after M. E. Evsevev, Studencheskaya St., 11a, Saransk, Mordovia, 430007, Russia \\ *Corresponding author E-mail: kondratyeva.n.p@mail.ru
}

\begin{abstract}
The purpose of the study is to determine the features of the value-semantic component of the psychological culture of students in early adolescence and the effect of training sessions on their change. The experimental study included the following steps: verifying, scheming and testing the training program. 32 students aged 16-17 were participants in the research. The main research methods were: theoretical, experimental, and diagnostic, as well as methods of mathematical data treatment. The paper highlights the features of the nature of the relations, values and meaningful orientations of students in early adolescence. Further, it gives the main aspects and results of approbation of the training and development of the value-rational component of the psychological culture of teenagers. It is proved that the implementation of a specially developed training program, including exercises for the development of a positive attitude towards others and oneself, meaningful orientations, and an awareness of the value orientations in life, contributes to the development of the value-rational component of the psychological culture of teenagers. The materials of this paper are of practical value for educational psychologists.
\end{abstract}

Keywords: Early adolescence; Meaningful orientations; Psychological culture; Value-rational component of psychological culture; Values-based orientations.

\section{Introduction}

In the modern world, there is an active search for ways to harmonize numerous and multifaceted polar manifestations: multiculturalism and traditionalism, freedom of conscience and the culture of building relationships, individual and public interests, as well as the virtual and real technologies of influence on human consciousness. In these conditions, attention to the psychological means of achieving stability, associated with the internal resources of an individual keeps growing. Therefore, the solution to the problem of the development of the psychological culture of an individual and its resource, as a value-rational component, acquires particular urgency.

The ideas of L.S. Vygotsky seem to be important insolving these issues. He stated that "any function in the cultural development of a child appears twice, in two aspects; first in a social plane and in a psychological plane, first among two people as an inter-psychic category, and then inside of a child as an intra-psychic category" [1, p. 145]. This thought was expressed about 90 years ago, just like some other important ideas on cultural and historical psychology proposed by Vygotsky (on the social situation of development, psychological neoplasms, signs and symbols as carriers of culture and sources of individual consciousness, etc.). However, this concept has now experienced a real renaissance throughout the world for in the last quarter of the XX century. At present, the discussion of the problems of culture and psychology has reached a new level on a world scale and is organized professionally. This is facilitated by a number of international conferences and forums, as well as specially created magazines of the same subject, which become discussion platforms and centers for the approbation of innovative ideas and solutions. Further, in the UK, since 1995, the magazine "Culture and Psychology" has been published in both print and online versions as a periodic international scientific publication of Sage Publications. Moreover, as of 2005, the magazine "Culturalhistorical Psychology" has been organized in Russia as a periodic international scientific publication of the Moscow State Psychological and Pedagogical University. This periodical publishes unusual research on the theoretical and methodological problems of cultural, historical and activity psychology, as well as previously unreleased archive materials of standard authors of Russian psychology. This proves the existence of a heightened interest in the formulation of problems on this topic and their solution at the global level.

V. Glăveanu and B. Wagoner, in the article dedicated to the twentieth anniversary of the publication of "Culture and Psychology," offered "to reflect on the development of ideas within the scope of the journal and the discipline of cultural psychology at large, as part of a look towards their future" [2, p. 429], encouraging researchers to promote the integration of ideas in time. In the same issue of this journal, J. Valsiner emphasized that we need an "extension of the content areas that belong to the meaning clusters of culture and psychology in ways that illuminate sciences that study human ways of being" [3, p. 419], while emphasizing the importance of creating an interdisciplinary discussion field.

Attempts of traditional psychology to become independent of 
culture are doomed to fail, because researchers, as well as the participants of their research, are representatives of certain cultures through which each of them has socialized. Given this circumstance, J. Smedslund highlights that "scientific psychology must operate from within a culture and must account for the common sense psychology embedded in that culture" [4, p. 443]. Science has many fruitful studies in which the relationship between various indicators of cultural and psychic phenomena is examined with a use of rich empirical material, in particular, revealing the influence of culture on cognitive processes. However, according to J. Altarriba, "they typically review ethnographic and observational studies conducted from an anthropological perspective" [5, p. 379]. At the same time, there is an obvious need for an interdisciplinary review of such problems, integrating the possibilities of anthropology, cognitive psychology, intercultural psychology, and linguistics.

D. R. Lehman, Ch. Chiu, and M. Schaller draw attention to another perspective that allows us to explore the mutual orientation of this connection and to reveal how psychological processes and culture affect each other. "Individual thoughts and actions influence cultural norms and practices as they evolve over time, and these cultural norms and practices influence the thoughts and actions of individuals" [6, p. 689].

A rich material for revealing the essence of these reciprocal relationships is found in cross-cultural studies that essentially enrich the psychological science with theoretical generalizations developed from a position of diverse cultural paradigms. In particular, the work of N. Gorlova, L. Romanyuk, L. Vanbrabant, and R. Schoot is of great interest, in which a cross-cultural study of meaningful orientations and values in two samples of students (Russians and Ukrainians) is characterized. However, according to the authors, "It is not unclear whether this test shows measurement invariance across different countries or not" [7, p. 744].

Within the framework of polyculturalism, research interest shifts and is not reduced to examining the influence of culture on mental life. The focus is on questions, the answers to which give the key to understanding the interaction of different cultures in the inner world of a particular person, who, without knowing it, becomes the environment for the emergence of interculturality. M.W Morris, Ch. Chiu, and Z. Liu emphasize that individually, each person experiences the influence of many cultures and thereby, becomes a channel through which cultures can influence each other. In connection with this, it is important to conceptually justify the fact of "how cultures are changed by contact with other cultures, enabling richer psychological theories of intercultural influence" [8, p. 631].

In recent years, Russian studies have intensively studied and constantly enriched the phenomenon of psychological culture, in relation to which I.V. Dubrovina points out that "... the core of a common culture is its psychological context" [9, p. 120]. According to the position of Ya. L. Kolominskiy, psychological culture reflects a certain level of self-knowledge of mankind, the relationship of a person to the surrounding people, to himself/herself, to nature as a whole [10].

L.S. Kolmogorova notes that psychological culture, having a complex structure, is part of the general culture of a person, which provides him/her not only with an understanding of the inner world of people, an effective solution of life psychological problems, adaptation and self-determination in society, but also, contributes to "self-realization, self-development, harmonization of the inner world and relations with others" [11, p. 33].

According to V. V. Semikin, psychological culture is "an integral personal characteristic that manifests itself in life activity and interaction with the world as a certain degree of personality development" [12, p. 22].

Analyzing the views of researchers on the structure of psychological culture of a person $[9 ; 11 ; 12 ; 13]$, one can distinguish the following minimal possible list of its components: cognitive (psychological knowledge and skills in relation to oneself and the surrounding reality), behavioral (practical application of psychological knowledge, skills, ability to interact effectively with others, regulate one's own behavior and emotional reactions, psychologically influence oneself and other people), and value-rational ones (the system of values, views, beliefs and relationships of man to the world around him and himself as an integral part of it). Features of these components and their individual aspects are considered by researchers in relation to various activities. For example, L. D. Maidokina and O. V. Kudashkina point to the significance and peculiarities of the development of athletes' self-regulation (behavioral component) [14].

Let us consider in more detail the value-rational component, which, according to many statements, is the "core" of psychological culture $[11 ; 12 ; 13]$. Different researchers in their own fashion define this component. In the studies of L. S. Kolmogorova, value-rational components of psychological culture are represented by a system of personally significant ideals, attitudes, and beliefs associated with the human psyche, its activities, relationships with others, etc. The author notes that "these are some "spiritual pillars" that give a person the meaning of life, orienting him/her in life, contributing to the confrontation of destructive and negative influences" [11, p. 16]. According to V. V. Semikin, the structure of this component of the psychological culture of the individual involves norms, human values and attitudes, as well as semantic personalities, worldview, and conscience [12]. K. M. Romanov defines the value-rational (spiritual-moral) component of psychological culture through stable human relationships to other people and to oneself, depending on the place in the system of values of the personality of other people (similar and equal personalities, tools (means) for solving personal or some other problems, etc.) [13]. Solving the problem of research and development of psychological culture, first of all, its value-rational component is the most relevant for the period of early adolescence. In the works of B.G. Ananyev [15], D.B. Elkonin [16], E. Erikson [17] and other scientists, we can see that early adolescence is a period of the formation of a system of values, world outlook, the meaning of life, and, in general, the professional and personal self-determination of a person.

Other case studies address complex communication issues that arise between context, culture and competence in influencing the process of development in a person's inner world. According to E. Elbers, "an adequate theory of the development of knowledge must explain the relationship between the spontaneous construction of knowledge by the child and the transmission of knowledge to the child" [18, p. 137]. On this basis, the author refers to the transfer of knowledge as a process in which children are provided with cultural views of reality. Thus, the question is raised about the possibility of children's participation in the creation of their own knowledge and intellectual development, to which a substantiated affirmative answer is given. Its extrapolation is possible when designing the expected effect of the training tasks in the empirical part of this study.

In the world of psychological science, the theoretical and practical foundations of psychological training have been developed, their developmental opportunities for various manifestations of mental life have been substantiated, the conditions and techniques for achieving their greatest effectiveness and preserving the relative stability of the received positive effect have been examined, and the ways of training psychological personnel for the successful application of training in solving professional tasks have been shown. In particular, V.V. Vandaveer, R.L. Lowman, K. Pearlman, and J.P. Brannick organized a study in which they succeeded in "(a) beginning to systematically investigate and identify the domain of knowledge, skills, abilities, and personal characteristics (KSAPs; i.e., "competencies") important for coaching by psychologists, and (b) developing a foundational competency model" [19, p. 118]. Thus, based on the practical analysis of the psychology of coaching, they created a competence model, in which the professional qualities of the psychologist-coach 
himself/herself and the strength of the relations built by him/her are considered as the key factors in the success of psychological training.

These factors are largely caused by the growing interest to the application of training for the development of various personality traits of students - future psychologists. Thus, in the study of Y.V. Vardanyan, L. V. Vardanyan, and E. A. Lezhneva, the possibilities of training to promote the realization and development of students' psychological safety are grounded. Characterizing its features, the authors emphasize that "training integrates professional and developmental tasks, the fulfillment of which develops achievement motivation" $[20$, p. 2$]$.

Training is one of the most effective forms of working with students in early adolescence [21]. Accordingly, training as an innovative psycho-pedagogical technology can be used to develop the value-rational component of the psychological culture of students in early adolescence. In this case, the technology of work will consist of the integrated preparation of the training program, its implementation in accordance with the principles of psychology, the principles of group interaction and the formation of a psychological culture of the individual, as well as evaluation of the effectiveness of the approved program.

Thus, in spite of numerous studies in the field on the understanding of psychological culture, its structural and content characteristics, functions and developmental features in ontogenesis, a unified concept for the definition and formation of this personal education has not been presented in the scientific literature. No studies have been found in which the content aspects of the value-rational component of the psychological culture of students of early adolescence and its purposeful development during the training sessions are comprehensively studied, which indicates the relevance of the research problem. The purpose of the study is to determine the features of the value-semantic component of the psychological culture of students in early adolescence and the effect of training sessions on their changes.

\section{Methods}

The experimental study included the following steps:

1) Verifying the experiment; the purpose of which was to reveal the initial level of the formation of the value-rational component of the psychological culture of teenagers.

2) Design and testing of the training program aimed at developing the value-rational component of the psychological culture of teenagers;

3) Checking the experiment; the purpose of which was to evaluate the effectiveness of the approved training program and to reveal changes in the level of formation of the studied component of the psychological culture of the subjects following a rediagnosis.

32 students of one of the general education lyceums of the city of Saransk (Russia) aged 16-17 years were involved as test participants.

The study used the following diagnostic tools: method: "unfinished sentences" (modified by L.S. Kolmogorova) [22]; test: "life-purpose orientations" (D.A. Leontiev) [23]; method: "value orientations" (M. Rokich) [24]. The selection of these tools was carried out, taking into account the need to identify the following parameters for assessing the formation of the value-rational component of the psychological culture of students in early adolescence: nature of relations, meaningful orientations, and value orientations. Mathematic-statistical treatment of the study data was carried out with the help of the criterion $\varphi^{*}-$ the angular Fisher transformation and Mann-Whitney U-criterion.

\section{Results}

The characteristics of the initial level of the value-rational component of the psychological culture of students in early adolescence begins with an analysis of the data in Table 1, showing the features of their character of relations (using the method of "unfinished sentences" in the modification of L.S. Kolmogorova).

Table 1: Valuation data of the relationship

\begin{tabular}{|c|c|c|}
\hline \multirow{2}{*}{ Nature of relations } & \multicolumn{2}{|c|}{ Number of participants } \\
\cline { 2 - 3 } & abs. & $\%$ \\
\hline Positive & 9 & 28.1 \\
\hline Neutral & 19 & 59.4 \\
\hline Negative & 4 & 12.5 \\
\hline
\end{tabular}

From the data of Table 1, it follows that more than half of the students surveyed in early adolescence $(59.4 \%)$ are dominated by a neutral relationship nature. They are manifested in the sphere of relations to the family ("My parents are people"); to friends and agemates ("I believe that my friends are like me", "My agemates with whom I study are my peers"); to teachers ("I believe that teachers are ordinary people"); to people ("Every person is different"); to myself ("When I look at myself in the mirror, I see my reflection"); to life ("My life is ordinary").

$28.1 \%$ of the participants, two times less than in the previous group, have a positive relationship. They are revealed in the sphere of relations to the family ("It seems to me that my family is the best"); to friends and agemates ("I believe that my friends are the best", "Peers with whom I study are very smart"); to teachers ("I believe that teachers are competent and wise"); to people ("Every person is talented"); to myself ("I think of myself as a real person"); to life ("A good life is my life").

The smallest number of participants are characterized by a negative relationship nature $(12.5 \%)$. They are distinguished in the sphere of relations to the family ("I do not respect parents for anything"); to friends and peers ("I believe that my friends are temporarily important people", "Peers with whom I study are inadequate people"); to teachers ("I believe that teachers are biased"); to people ("Every person is a Manchurian candidate"); to myself ("When I look at myself in the mirror, I see a person who is worth changing").

Next, we consider the data of Table 2, which represents the features of the meaningful orientations of students in early adolescence (according to D.A. Leontyev's "life-purpose orientation" test).

Table 2: Estimates of the levels of life-purpose orientations

\begin{tabular}{|c|c|c|}
\hline Level of & \multicolumn{2}{|c|}{ Number of participants } \\
\cline { 2 - 3 } life-purpose orientations & abs. & $\%$ \\
\hline High & 8 & 25 \\
\hline Medium & 22 & 68.8 \\
\hline Low & 2 & 6.2 \\
\hline
\end{tabular}

From the data of Table 2, it follows that the largest part of the surveyed students in early adolescence (68.8\%) have an average level of life-purpose orientations. They really appreciate the possibility of achieving the life goals that they set for themselves, and reinforce them with their own responsibility. However, they live for today and only dream of achieving something greater in the future. A quarter of the participants (25\%) showed a high level of life-purpose orientations and meaningfulness of life, which means having clear goals that provide meaning, direction and perspective. The smallest part of the participants $(6.2 \%)$ have a low level of life-purpose orientations, the conviction that human life is not subject to conscious control and they do not live as emotionally saturated characters or set long-term goals.

From the evaluation of terminal values obtained using the methodology "value orientations" (M. Rokich), it follows that the most significant for most of the participants are health, love, happy family life, freedom, self-confidence, and development. Creativity, interesting work, happiness of others, vital wisdom, 
active life, and cognition are referred to somewhat less significantly. The least important for the participants are a comfortable life with money, a productive life, pleasures, the presence of good and faithful friends, public recognition, as well as the beauty of nature and art.

According to the indicators of the methodology, students in early adolescence attach the greatest importance to the astract group of terminal values, the values of personal life, and the least to specific values and values of professional self-realization.

The data obtained from the evaluation of instrumental values indicate that the most significant for the majority of participants are honesty, upbringing, education, independence, cheerfulness, and breadth of views. Somewhat less significant values include self-control, courage in defending one's opinion, diligence, responsibility, firm will, and rationalism. The least significant values are sensitivity, efficiency in matters, tolerance, accuracy, intransigence to shortcomings in themselves and others, and high demands.

The data obtained show that students in early adolescence attach the greatest importance to the values of communication, conformist values, values of self-affirmation and acceptance of others; the least are to altruistic values.

Thus, during the verifying stage of the study, it was revealed that the majority of students in early adolescence have a neutral and negative nature of relations towards the surrounding world and to themselves, as well as medium and low levels of life-purpose orientations. They are oriented primarily towards themselves and achieving personal goals with a lack of awareness of one's own responsibilities for this. In this connection, there was a need to implement a training aimed at increasing the level of the formation of the value-rational component of the psychological culture of students of early adolescence through the development of their values and life-purpose orientations, as well as a positive attitude towards others and themselves.

On the basis of the obtained data, two groups (experimental and control) were formed, each of which included 16 students in early adolescence. The experimental and control groups did not have statistically significant differences in the majority of indicators of the formation of the value-rational component of psychological culture, with the exception of the terminal values, "public recognition" and "self-confidence". The difference was revealed at a five percent level of significance $(p \leq 0,05)$ ( values are chosen in the control group more often than in the experimental group), as well as instrumental values "tidiness", "cheerfulness", and "independence", where the difference is revealed at a $5 \%$ level of significance $(p \leq 0,05)$ and the value of "intolerance of shortcomings in themselves and others" at the $1 \%$ significance level $(p \leq 0,01)$. The values of "cheerfulness" and "independence" are selected in the control group more often than in the experimental group, and the values of "tidiness" and "intolerance to shortcomings in themselves and others" are the other way round.

The training was conducted with the students of the experimental group, the purpose of which was the development of the valuerational component of their psychological culture. In accordance with the goal, the following training objectives were defined:

1) To promote the development of a positive attitude in students in early adolescence towards others and themselves as individuals;

2) Create favorable conditions for students to understand the early youthful values of their own priority values in life and focus on the humane aspects of value orientations;

3) To promote the development of meaningful orientations in the students in early adolescence.

The hypothesis of the research consisted in the assumption that the implementation of a specially developed training program, including exercises to develop a positive attitude towards others and oneself, meaningful orientations, and an awareness of the value orientations in life, contributes to the development of the value-rational component of the psychological culture of students in early adolescence.
When creating and further implementing the program of the training, the following principles of psychology and the formation of the psychological culture of the individual were observed:

1) The principle of taking into account the individual psychological traits of the training participants (in the process of developing and approving the training program, the findings of the verifying stage of the study were taken into account);

2) The principle of accounting for the volume and content of training materials (the training materials were optimal in terms of scope, varied, meaningful, and consistent with the solution of the indicated tasks);

3) The activity approach (the content of the training program is represented by various activities in the implementation of exercises, participation in organized discussions, the analysis of video materials reviewed, and the verbalization of ideas about the future, etc.);

4) The involvement principle (during the training sessions, the activity was organized in such a way as to involve each participant in the work while training, to achieve the interest of the group to the problem of assimilation of the components of the psychological culture, to promote reflection of attitudes and achievements);

5) The principle of consistency (integrity) (developing a positive attitude towards themselves and the world around them, meaningful orientations and value orientations, the participants of the training acquire a certain amount of psychological knowledge and skills in their interaction with a psychologist and with each other over the course of interpersonal interaction);

6) The principle of reliance on the experience of a person in the field of everyday psychology (during the design and implementation of training, examples of life, videos and cartoons that correspond to the topic of training sessions were selected and cited).

The training included thirteen sessions and was designed to be held for two months at a frequency of meetings twice a week. Each lesson lasts 1.5 hours.

The training was designed on the basis of general provisions described in the psychological and educational literature on the development of training programs. In addition to the author's exercises, it included exercises from other scientific sources [25; 26]. The training program consisted of three parts:

1. The introductory (motivational) part was represented by one training activity and was aimed at an acquaintance, establishing psychological contact with participants in the training, and creating motivational readiness for participation in the work.

2. The main (working) part included eleven training sessions and was focused on solving the tasks of training by dividing the students into more particular aspects.

3. The last (final) part was represented by one training session and was designed to summarize the implementation of the training, creating conditions for its positive completion.

Let us present the main content and technologies of several training sessions of the main part of the program. The tasks of classes No 7-8 within the framework of the training were:

- formation of meaningful ideas about the concepts of "meaning of life" and "meaningful orientations" among the training participants;

- development of the group's ability to define and share the terms "meaning of life" and "meaningful orientations";

- promoting awareness of the role of meaningful orientations in human life;

- facilitating the participants' awareness of their own life position. The technologies for solving these problems included technology of psychological information and consulting (explanation and discussion of the content aspects of the concepts of "meaning of life" and "meaningful orientations", conversation-visualization about the meaning of life, ways to achieve priority goals); psychoprophylactic and developing technologies (represented by the exercises "exaggeration", "pass a thing" [25], "bus" [26], "thematic sketch", - author's technologies with running and 
subsequent analysis of the cartoon "On the meaning of life", and the movie-reel, "Parable of life. Values in human life").

The tasks of lessons No 9-12 were:

- development of a holistic view of the students themselves and their lives;

- promoting awareness and taking responsibility for one's life;

- development of planning skills for future life goals.

The technologies for solving the indicated problems in all occupations were: technology of psychological information and consulting (presented in each of the training sessions in the form of talks, explanations, instructions, etc.); psychoprophylactic and developing technologies (represented by the exercises "break in a circle", "packing a suitcase" [25], "I want-I can-I must", "arrow of life", "goals and matters" [26], "past-present-future", "lifeline", "your life", "my life journey", "achieving the goal", "planning the future" - author's technologies).

After conducting training sessions within the framework of the implementation of the check experiment, in order to evaluate the effectiveness of the approved training program, diagnostics were again carried out using the previously mentioned diagnostic tools. According to the methodology of "unfinished sentences" (modified by L.S. Kolmogorova), the positive nature of the relationship to oneself and the environment began to prevail in the largest part of the experimental group $(81.3 \%)$, while among the students in the control group, the number of participants with this nature of relations remained the same $(31.3 \%)$. Significant differences between the students of the two groups were also revealed by the number of those who demonstrated the neutral nature of the relationship; $12.4 \%$ in the experimental group and $56.3 \%$ in the control group. Finally, $6.3 \%$ of participants in the experimental group had the negative character of the relationship, while in the control group, there were twice as many $-12.4 \%$. The statements of participants from the experimental group, compared with the control one, became more correct and benevolent when the unfinished proposals were completed. Statistically significant differences between students of early adolescence of both groups were identified by the indicators "positive character of the relationship" $(\varphi *$ emp $=2.998)$ and "neutral character of the relationship" $(\varphi *$ emp $=2.754)$ at a $1 \%$ level of significance $(\mathrm{p} \leq 0.01)$.

According to the "life-purpose orientations" test (D.A. Leontyev), the highest level of meaningful orientations prevails in the largest part of the experimental group (75\%), while in the control group, only a third of students had it $(31.3 \%) .18 .8 \%$ of the participants in the experimental group and a significant number $(62.5 \%)$ of the students in the control group had an average level of meaningful orientations. A low level of development of meaningful orientations was observed in the same number of participants in the experimental and control groups $(6.2 \%$ each). Statistically significant differences between the participants of both groups were revealed by the indicators "high level of development of meaningful orientations" $\left(\varphi{ }_{\text {emp }}=2.565\right)$ and "average level of development of meaningful orientations" $\left(\varphi *_{\mathrm{emp}}=2.619\right)$ at a 1 $\%$ level of significance $(\mathrm{p} \leq 0.01)$.

According to the data of the method "value orientations" (M. Rokich), along with those statistically significant differences between the test participants of the experimental and control groups, which were recorded after the verifying stage, similar differences in terminal values were at the check stage of the study, including "active life" ( $\left.U_{\text {emp }}=76\right)$, "productive life" $\left(\mathrm{U}_{\mathrm{emp}}=\right.$ 74.5), "interesting work" ( $\left.U_{\text {emp }}=73.5\right)$, "happy home life" $\left(U_{\text {emp }}\right.$ $=80)$, "good and faithful friends" ( $\left.U_{\text {emp }}=81.5\right)$, "development" $\left(\mathrm{U}_{\mathrm{emp}}=79\right)$, "happiness of others" $\left(\mathrm{U}_{\mathrm{emp}}=76.5\right)$, as well as the following instrumental values: "tolerance" $\left(\mathrm{U}_{\mathrm{emp}}=73\right)$, "responsibility" $\left(U_{\mathrm{emp}}=77.5\right)$, "rationalism" $\left(\mathrm{U}_{\mathrm{emp}}=72\right)$, "efficiency in matters" ( $\left.U_{\text {emp }}=76.5\right)$, "sensitivity" ( $\left.U_{\text {emp }}=74.5\right)$, "courage in upholding one's opinion" $\left(\mathrm{U}_{\mathrm{emp}}=82\right)$ at a five percent level of significance $(p \leq 0.05)$. In all cases, this was due to an increase in the rank of the indicated values in the participants of the experimental group.

\section{Discussion}

The data from the control phase of the study showed that the majority of participants in the experimental group were predominantly positive about themselves and the world around them, while the control group's students had a neutral relationship. For the largest part of the experimental group, a high level of development of meaningful orientations has become characteristic. They began to have more clear ideas about their own life goals and more adequately assessed their personal abilities and the opportunities to achieve them, as well as placing responsibilities on themselves and their resources. In terms of the choice of terminal and instrumental values, the students of the experimental group, after participating in the training, were guided not only by personally significant needs but also, took into account the interests of the surrounding people. These changes indicate the effectiveness of the developed program for the development of the value-rational component of the psychological culture of students of early adolescence.

The analysis of available sources indicates that the researchers studied and developed either the psychological culture in general or certain aspects (values, meaningful orientations) of the valuerational component of the psychological culture of students of early adolescence. Thus, L. S. Kolmogorova, comparing the spontaneous and purposeful development of psychological culture by students of early adolescence, noted that participants who studied the discipline "humanity" are characterized by a greater harmony of values; however, according to meaningful orientations, there are no statistically significant differences to those who did not study the course [11]

The data of the carried out research proves that a carefully thought out and developed training program as a method of active sociopsychological training contributes to a positive change in the various components of the value-rational component of the psychological culture of students in early adolescence, which testifies to the scientific novelty and practical significance of the study.

Based on the results of the study, the definition of its basic concept was clarified: the value-rational component of psychological culture is the central link in the structure of the psychological culture of the individual, formed by the system of human relations with the surrounding world and himself, as well as by values and meaningful orientations.

\section{Conclusion}

Thus, as a result of the research:

1) The definition of the concept of "value-rational component of psychological culture" was clarified; some features of the valuerational component of the psychological culture of students in early adolescence are singled out and the need for its further development is shown;

2) A training has been developed which, having an appropriate goal, tasks, and structure, is focused on the observance of the principles of psychology and the formation of a psychological culture of the individual. Each fragment of the training sessions, having certain tasks, creates a psychological support for the solution of the tasks of the subsequent classes and the achievement of the goal of the training. The training program combines different technologies and offers a number of authorial exercises. The implementation of the training took place in an active form, as students of early adolescence were interested in the activities proposed to them

3) Repeated diagnostics of the components of the value-rational component of the psychological culture of students of early adolescence and the mathematical treatment of the research data allowed us to state statistically significant differences in the nature of relations, terminal and instrumental values, and the level of meaningful orientations of the experimental and control group 
participants. Thus, the hypothesis of the study was confirmed. The implementation of a specially developed training program, including exercises to develop a positive attitude towards others and themselves, meaningful orientations, and awareness of value orientations in life, contributes to the development of the valuerational component of the psychological culture of students of early adolescence.

Research materials can be used by practical psychologists of education in order to improve the personal development of students in early adolescence.

The possibility of developing a psychological culture as a whole and its value-semantic component, in particular, taking into account the multidirectional intensifying influence of the experience of virtual relationships on the content of the developed component of the psychological culture of modern students in early adolescence, can be referred to in the perspective of the research.

\section{Acknowledgement}

The research was carried out within the framework of a grant for conducting scientific research on priority areas of scientific activity of partner universities in network interaction (South Ural State Humanitarian Pedagogical University and the Mordovian State Pedagogical Institute, named after M.E. Evsevieva) on the theme, "development of the value-rational component of the psychological culture of youth".

\section{References}

[1] Vygotsky L (2015), Mind in society: The development of higher psychological processes. Cambridge, MA: Harvard University Press. 1978.

[2] Glăveanu V \& Wagoner B, Culture \& Psychology: The first two decades and beyond. Culture and Psychology, 21(4), 429-438

[3] Valsiner J (2015), Where are you, Culture \& Psychology? Making of an interdisciplinary field. Culture and Psychology 21(4), 419428.

[4] Smedslund J (1984), The Invisible Obvious: Culture in Psychology. Advances in Psychology 18, 443-452.

[5] Altarriba J (1993), The Influence of Culture on Cognitive Processes. Advances in Psychology 103, 379-384.

[6] Lehman DR, Chiu Ch \& Schaller M (2004), Psychology and Culture. Annual Review of Psychology 55(1), 689-714.

[7] Gorlova N, Romanyuk L, Vanbrabant L \& Schoot R (2012), Meaning-in-life orientations and values in youth: Cross-cultural comparison. European Journal of Developmental Psychology 9(6), 744-750.

[8] Morris MW, Chiu Ch \& Liu Z (2015), Polycultural Psychology Annual Review of Psychology 66(1), 631-659.

[9] Dubrovina IV (2013), Psikhologicheskaya kul'tura lichnosti kak tsel' i smysl psikhologicheskogo obrazovaniya [Psychological Culture of Personality as the Purpose and Meaning of Psychological Education]. Izvestiya Rossiiskoi Akademii obrazovaniya 2, 114-129.

[10] Kolominsky YaL \& Seleznev AA (2011), Vzaimosvyaz psikhologicheskoy kul'tury i psikhologicheskogo zdorov'ya lichnosti kak nauchno-prakticheskaya problema [Interrelation of psychological culture and psychological health of a person as a scientific and practical problem]. Psychiatry, psychotherapy and clinical psychology 4, 120-130.

[11] Kolmogorova LS (2001), Vozrastnyye vozmozhnosti i osobennosti stanovleniya psikhologicheskoy kul'tury uchashchikhsya [Age opportunities and features of formation of the psychological culture of students]. Lomonosov Moscow State University, Moscow.

[12] Semikin VV (2002), Psikhologicheskaya kul'tura v obrazovanii cheloveka [Psychological culture in human education]. SaintPetersburg: Piter.

[13] Romanov KM (2012), Psikhologicheskaya kul'tura: problemy i perspektivy issledovaniya [Psychological culture: problems and prospects of research]. Psychological culture of a person: theory and practice: proceedings of All-Russian research/practice conference, Mordovian university. Saransk, 59-76.
[14] Maidokina LG \& Kudashkina OV (2014), Razvitiye samoregulyatsii sportsmena $\mathrm{v}$ sisteme yego psikhologicheskoy podgotovki [Development of self-regulation of the sportsman in the system of his psychological preparation]. Theory and practice of physical culture $8,18-21$

[15] Ananyev BG (1957), O sisteme vozrastnoy psikhologii [About the system of age psychology]. Questions of psychology 5, 16-24.

[16] Elkonin DB (1971), K probleme periodizatsii psikhicheskogo razvitiya $\mathrm{v}$ detskom vozraste [On the problem of periodization of mental development in childhood]: Questions of Psychology 4, 3951.

[17] Erikson E, Identity: Youth and Crisis. New York, London: W. W. Norton \& Company, 1968.

[18] Elbers E (1991), Context, culture, and competence: Answers to criticism. Educational Psychology Review 3(2), 137-148.

[19] Vandaveer VV, Lowman RL, Pearlman K \& Brannick JP (2016), A practice analysis of coaching psychology: Toward a foundational competency model. Consulting Psychology Journal: Practice and Research 68(2), 118-142.

[20] Vardanyan YV, Vardanyan LV \& Lezhneva EA (2014), Influence of Training in Psychological Safety on Development of Motivational Basis of Student's Professional Strategy. Ciencia e Tecnica Vitivinicola 29(12), 2-11.

[21] Dolgova VI, Baryshnikova EV \& Popova EV (2015), Innovatsionnyye psikhologo-pedagogicheskive tekhnologii v rabote so starsheklassnikami [Innovative psycho-pedagogical technologies in work with high school students]. Moscow: Pero.

[22] Kolmogorova LS (2002), Diagnostika psikhologicheskoy kul'tury shkol'nikov: prakticheskoye posobiye dlya shkol'nykh psikhologov [Diagnostics of the psychological culture of schoolchildren: practical guide for school psychologists]. Moscow: Vlados-Press.

[23] Leontyev DA (2000), Test smyslozhiznennykh oriyentatsiy [Test of meaningful orientations (TMO)]. Moscow: Smysl.

[24] Karelin AA (2009), Bol'shaya entsiklopediya psikhologicheskikh testov [A great encyclopedia of psychological tests]. Moscow: Eksmo.

[25] Gretsov AG (2011), Treningi razvitiya s podrostkami. Tvorchestvo, obshcheniye, samopoznaniye. [Developmental trainings with teenagers. Creativity, communication, self-knowledge]. SaintPetersburg: Piter.

[26] Shkilev SV (2006), Smyslozhiznennyye oriyentatsii kak faktor sotsial'no-psikhologicheskoy adaptatsii studentov $v$ protsesse obucheniva $v$ vuze [Life-purpose orientation as a factor of sociopsychological adaptation of students in the learning process in the university]: thesis work, Candidate of Psychological Sciences, State University. Belgorod. 